\title{
ESTUDIOS
}

\section{Sobre la necesidad de las humanidades en la forma- ción académica}

\section{María del Carmen Molina Barea'}

Resumen: El presente artículo tiene por objeto plantear un acercamiento a la coyuntura actual de las humanidades en el ámbito académico, no entendiéndolas sólo como titulaciones propias sino muy especialmente como contenidos docentes presentes en otras materias; y a partir de ello analizar las razones de su alarmante y progresiva desaparición en este contexto. Se busca así mismo facilitar una serie de propuestas que, a modo de puntos básicos, ayuden a ilustrar la imperiosa necesidad de la revalorización e inclusión de las humanidades en la formación de la enseñanza superior.

Palabras clave: Humanidades, universidad, formación integral, transversalidad, espíritu crítico, pensamiento creativo, innovación.

Fecha de recepción: 8 de enero de 2014 .

Fecha de admisión: 12 de junio de 2014.

\footnotetext{
' Departamento de Ciencias Sociales y Humanidades. Universidad de Córdoba. mcpalladio@hotmail. com 
On the necessity of the humanities in academic training

\begin{abstract}
This article aims to present an approach to the current situation of $\mathrm{Hu}$ manities in academia, not understanding them only as own degrees but especially as teaching contents present in other subjects. From this pointwe analyze the reasons of their alarming and progressive disappearance. The intention here is to provide some basic suggestions which help to show the urgent need in appreciate and include Humanities in higher education formation.
\end{abstract}

Key words: Humanities, college, comprehensive training, mainstreaming, critical thinking, creative thinking, innovation.

\section{Sur la nécessité des sciences humaines dans la formation académique}

Résumé: Cet article vise à présenter une approche à la situation actuelle des sciences humaines dans les universités, ne pas les comprendre seulement comme propres diplômes mais surtout que l'enseignement de contenu présents dans d'autres sujets; et de celle d'analyser les raisons de la disparition alarmante et progressive dans ce contexte. L'intention ici est de fournir une série de propositions qui, pour l'essentiel, aider àillustrer la nécessité urgente pour l'appréciation et l'inclusion des sciences humaines dans la formation de l'enseignement supérieur.

Mots clé: Sciences Humaines, université, formation complète, intégration, pensée critique, pensée créatrice, innovation.

\section{El estado de la cuestión: una aproximación a la problemática}

Sírvanos resumir al comienzo del artículo el sentir y el convencimiento del mismo en una sencilla expresión: las humanidades se encuentran hoy día en peligro de extinción. Aun sonando hasta cierto punto categórico, probablemente ningún lector se sorprenderá de esta afirmación. En caso de que lo hiciera, tendría que luchar contra la evidencia de una realidad que se impone arrolladora por lo contundente de sus manifestaciones. Las humanidades no gozan en la actualidad de especiales privilegios, ni son -qué duda cabe- las enseñanzas predilectas de un sistema educativo que desde sus cimientos y niveles más primarios, llegando significativamente a los superiores, resta cada vez mayor importancia y presencia a materias relacionadas con la literatura, la filosofía, el arte o la historia. Esta tónica decanta en un perfil concreto de formación universitaria, que reserva el pódium a las ciencias experimentales y técnicas, y concede el premio de consolación a las ciencias humanísticas. Utilidad y rentabilidad son los principios que justifican esta 
práctica, sustentada en la idea, tantas veces falseada, de una directa aplicación laboral. La consecuencia más inminente es, en realidad, la pérdida irremplazable de habilidades que sólo el conocimiento humanístico puede aportar, y que abarcan recursos de comprensión transversal, aprendizaje progresivo, crítica constructi$\mathrm{va}$, pensamiento alternativo, creatividad e invención, reflexión, etc., igualmente requeridos para el adecuado progreso de las ciencias técnicas. $Y$ es todo esto, por tanto, lo que nos lleva a subrayar la urgencia de incrementar los contenidos humanísticos en la formación académica, independientemente de las disciplinas de especialización; siendo muchas las razones para argumentar el estado actual de marginación de las humanidades, y abundantes para respaldar, por ende, su recuperación y necesidad.

A continuación, en el punto 2 del presente trabajo se expondrán las causas de esa "unilateralidad intelectual" -que diría Fernando Savater- que lleva a violentar el funcionamiento de las enseñanzas humanísticas, así como las causas en virtud de las cuales nos encontramos capacitados para hablar de las humanidades como víctimas de una noción de practicidad mal entendida, orientada al beneficio capitalista bajo el disfraz de una mayor rentabilidad y una inserción laboral más exitosa que la que se le atribuye a las humanidades. Seguidamente, en el punto 3, y a lo largo de varios subapartados, se procederá a presentar los motivos principales que amparan la reparación de las materias humanísticas en el contexto académico, desgajando las cualidades inherentes a estos estudios y su utilidad imperecedera para el positivo avance de la sociedad, la técnica y la ciencia aplicada, más allá de criterios exclusivistas de rendimiento económico a corto plazo. De hecho, el abanico de características que le es propio a las humanidades será, como veremos, la solución a la cerrazón de miras y escasez de recursos que se derivan de este posicionamiento mercantilista de la educación superior, y el salvoconducto para el desarrollo de un tipo de especialización capaz de superar sus propias limitaciones de definición y planteamiento.

\section{2. ¿Por qué decimos que las humanidades están en peligro de extinción?}

En el año 1998, miembros del Área de Estudios e Investigación del Centro de Investigación y Documentación Educativa (CIDE) se planteaban un interrogante - "¿Hay lugar para la enseñanza de las humanidades en la Europa del siglo XX|?" con el cual titulaban un artículo que iniciaba sus líneas afirmando un hecho de indudable vigencia: 
No corren buenos tiempos para las humanidades. En realidad no son buenos tiempos para nada que tenga un cariz de gratuidad, para nada aparentemente "inútil", para lo no cotizable en el mercado. La educación no escapa al economicismo reinante en todas las esferas sociales y en cualquier parte del mundo sus fines y regulación se ven tan afectados por él como cualquier otra actividad humana. ${ }^{2}$

Lo que los autores referían también como "orientación productivista de la educación" es la preocupación evidente de buena parte del profesorado, personal docente e investigador, de humanidades en España desde hace décadas, como ha venido demostrándose a lo largo de los últimos años con la organización de periódicas jornadas y congresos centrados en el rol que desempeñan las humanidades en la vigente sociedad posmoderna y su papel, cada vez menor, en el escenario académico. Así por ejemplo, con motivo de la celebración en el año 2010 del Congreso "Las Humanidades en España y en Europa. Retos y oportunidades de la convergencia europea en la educación superior y en la investigación", bajo la organización de la Universidad Complutense de Madrid y el Instituto de Filosofía del CSIC, y la colaboración, entre otros, de la Fundación Instituto José Ortega y Gasset, el prof. Javier Zamora Bonilla, de la Facultad de Ciencias Políticas y Sociología de la Universidad Complutense, aludía asimismo a la creciente inquietud por la pérdida de peso de las materias humanísticas frente a las ciencias experimentales o exactas, de lo cual es innegable indicio-aunque no el único- la reducción de horas de asignaturas como filosofía, historia, historia del arte, etc.

De igual forma, hacía claro Zamora Bonilla que

El valor añadido de los estudios humanísticos no es necesariamente inmediato ni fácilmente cuantificable, por lo que no tiene sentido aplicar parámetros de medición válidos para otro tipo de ciencias. Los resultados de la investigación y de la formación humanísticas, sobre todo en términos sociales, suelen producirse a medio y largo plazo. ${ }^{3}$

La inclinación mercantilista de la educación superior se convierte en un poderoso elemento de corrosión de la componente humanística de las enseñanzas universitarias, dada la insistencia en canalizar los "índices productivos" de esta rama en mediciones equivalentes a otras de diferente carácter, a la búsqueda de resultados productivos económicamente rentables o al menos equiparables a los demás. Es lo que el prof. Javier Moscoso, del Instituto de Filosofía del CSIC, explica como la progresiva amenaza de una ideología de los grandes números que sólo defiende

${ }^{2}$ M. MUÑ̃Z-REPISO y otros (1998), p. 209.

${ }^{3}$ J. ZAMORA BONILA (2010), p. 4 
y acepta métodos cuantitativos de investigación. ${ }^{4} \mathrm{~A}$ este respecto, en su conferencia "El papel de las humanidades en la educación democrática", impartida en la Facultad de Filosofía y Letras de la Universidad de Córdoba en abril de 2012, Fernando Savater señalaba que cada vez más tiende a confundirse en el ámbito académico lo útil con lo rentable, siendo este peculiar fenómeno un elemento clave en el modo en que nos aproximamos en la actualidad a la comprensión del ser mismo de las humanidades, y en la manera en que se las gestiona legislativa y académicamente.

La tan manida pregunta, formulada habitualmente entre los jóvenes estudiantes de hoy, de "¿para qué sirven las humanidades?" es por sí misma claro síntoma de una sociedad y una época que, bajo nuevos cánones y horizontes deseables, ha extraviado lo que hasta no hace tanto constituía un compendio de motivos de tal rotundidad y un convencimiento positivo que de tan evidente, no cabía siquiera interrogar. El por qué de las humanidades era algo incuestionable, tan fácil se comprendían su utilidad y beneficio. Sin embargo, parece que hoy día ya no se aprecian tan fácilmente; no logramos encontrar la utilidad de las humanidades, no entendemos que tengan un beneficio: "¿para qué sirven?". Aunque a la luz de nuestros días resulte ya difícilmente asimilable, lo cierto es que las humanidades han venido considerándose siempre materias prácticas para la sociedad y útiles para la persona. Ocurre, sin embargo, que dicho término, "utilidad", ha experimentado en tiempos recientes una sustancial mutación, que la ha hecho pasar de su original acepción de "sentido" o "valor" a adoptar una perversa pátina de connotaciones economicistas. Así pues, podemos decir que las humanidades han tenido (y siguen teniendo -pensamos algunos, esperanzados-) un sentido, que no tanto una utilidad, de acuerdo al significado actual de la palabra. Ahora bien, tampoco sería de recibo restar a las humanidades su también existente potencial de repercusión económica y social, pues si bien no es éste comparable, por diferencias evidentes, al de otras materias académicas, no significa que no lo posea o que no deba ser debidamente desarrollado. Pero el problema es, como decíamos antes, y volviendo a Savater, que lo que no puede tasarse de la misma manera que las ciencias no humanísticas no le resulta útil al sistema, no le parece rentable, y en consecuencia no le merece la pena; directamente no sirve.

Este "¿para qué sirven?" da, pues, poderosas pistas de los pilares que sostienen el mundo en el que vivimos. Por eso, el hecho de que hoy se pregunte, por ejemplo, "¿para qué sirve la filosofía?", "¿para qué sirve la historia?" o "¿para qué sirve la

${ }^{4}$ J. Moscoso (2013), p. 3. 
historia del arte?" es algo de por sí revelador. Pone perfectamente de manifiesto el resultado generalizado de haber proyectado sobre las enseñanzas universitarias un filtro desvirtuado, el cual, pretendiendo una, por otro lado loable, actualización del mecanismo educativo, ha deformado las virtudes que éste poseía: la formación integral. Lastrada por un sentido de la practicidad en su traducción economista, la universidad tiende a convertirse -estamos asistiendo a ello- en un espacio para el aprendizaje técnico o de herramientas para fines de inmediata y tangible -más bien tasable- aplicación productiva, y ha visto progresivamente arrebatársele los contenidos que no casaban con esta idea o que ralentizaban este objetivo. Una peculiar situación para el funcionamiento académico nace como derivado de esta voluntad -llamémosla- mercantilista, evidenciándose en principios que buscan acuciantemente pautas de calidad, excelencia y competitividad, mientras parece olvidar criterios básicos ya desarrollados desde antiguo que, aun sonando a oxímoron, venían a sustentar una formación académica de calidad. Esto no quiere decir que dicho sistema tradicional debiera perpetuarse. Deviene una obviedad que todo sistema educativo necesita de mejoras y rectificaciones para conducirse satisfactoriamente y adecuarse a las demandas profesionales y de empleabilidad de su época y sociedad. Lo que resulta una verdadera lástima -verdadera injusticiaes que para lograrlo haya que poner en una balanza los beneficios del sistema que se estima caduco por un lado, y por otro las reformas del que nos promete solventar sus lagunas, decidiéndonos radicalmente por éste último platillo, como los tiempos nos llevan a creer.

A este respecto, Zygmunt Bauman remite al exhaustivo análisis que Carmel Borg y Peter Mayo realizan del "Memorando sobre el aprendizaje permanente" que elaborara la Comisión Europea en el año 2000, en el cual ponen de relieve que, más allá de engañosas cortinas de humo,

[...] los mensajes del memorando deberían ser interpretados considerando el trasfondo económico particular que supone la definición "mercantil" del concepto de viabilidad social. Los cambios educativos se vinculan así de forma creciente al discurso de la eficiencia, la competitividad, la rentabilidad y la rendición de cuentas [...]. ${ }^{5}$

Todo esto se traduce directamente en lo que Edward Said da en llamar el "triunfo de la ética del profesionalismo"; algo así como el imperio de las "abilities". Jordi Llovet, citando a Bertrand Russell, reflexiona también sobre esta realidad cuando en La conquista de felicidad (1930) afirmaba el Premio Nobel de Literatura que

${ }^{5}$ Z. BAUMAN (2006), p. 162. 
Uno de los defectos de la educación superior moderna es que se ha convertido en puro entrenamiento para adquirir ciertas habilidades y cada vez se preocupa menos de ensanchar la mente y el corazón [de los estudiantes, pero también de los profesores] mediante el examen imparcial del mundo. ${ }^{6}$

Y sin embargo, una cosa no tendría por qué implicar necesariamente desatender la otra. ¿2Por qué descuidar el aspecto humanístico e impulsar el técnico? ¿2Son acaso incompatibles y sólo puede desarrollarse uno en detrimento del otro? Realmente no debiera ser tan complicado fusionar ambas vertientes. Lo cierto es que, a pesar de todo, nos movemos a paso acelerado hacia el abrazo total con la practicidad de aplicación técnica, en paralelo al abandono absoluto de lo que los prejuicios de mercado nos han hecho creer inútiles; en una palabra, todo contenido formativo relacionado con las humanidades.

Las consecuencias directas de esta "filosofía" se rastrean sin demasiada dificultad en varias líneas de actuación orientadas a minar el valor y presencia de las humanidades; una "política" concreta puesta en marcha desde tiempo atrás, con no poca repercusión en nuestros días. Por un lado, consiste en restar importancia a las humanidades en el subconsciente colectivo, infravalorando en la escena social actual los aportes fundamentales que éstas entrañan. De este fenómeno proviene lógicamente la famosa pregunta de "¿para qué sirven?"... También se concreta en medidas implementadas para adelgazar los recursos económicos, tanto públicos como privados, en forma de subvenciones destinadas a formación humanística, becas de estudio o ayudas a la investigación en humanidades. Finalmente, se aprecia en una tendencia arrolladora por reducir horas y eliminar carga lectiva de materias humanísticas en programas docentes; o más tajantemente, por suprimir titulaciones propias de este tipo de estudios. Testimonio esclarecedor de esto han sido los variados intentos de recortar asignaturas de la rama de humanidades en bachillerato o universidad; desde los amagos del ministerio de $M^{a}$ Jesús San Segundo por menguar la Filosofía en bachiller, a las desapariciones de carreras de humanidades en la conversión al Grado, sin olvidar las polémicas implicaciones de la LOMCE o ley Wert, que tan de cerca nos toca. Todo ello movidos por la creencia de una utilidad o aplicación laboral inmediata, que hace volcarnos en el cultivo de las ciencias técnicas marginando el de las humanísticas. Por eso en el capítulo 5 de El valor de educar, titulado " ¿Hacia una humanidad sin humanidades?", criticaba Savater la desaparición de los planes de estudio de humanidades, sustituidos por especialidades técnicas, por cuyo autismo académico sobrevendrán carencias esenciales en el alumno (habilidades reflexivas, sentido crítico, inclinación creativa,

6 J. LLOVEt (2011), p. 29. 
saber histórico) que afectarán a generaciones sucesivas. No se dan cuenta-afirma el prof. Ramón Román, del Departamento de Ciencias Sociales y Humanidades de la Universidad de Córdoba- que cuando se dota a nuestros alumnos de sólo estas herramientas útiles, olvidándose de la filosofía, descuidan el pensamiento crítico, la empatía, la comprensión de la injusticia, y la felicidad?

\section{Necesidad de las humanidades en la formación académica}

Una vez radiografiada la problemática que acucia la realidad de las humanidades en el contexto académico, pasamos a continuación a exponer en tres puntos principales las ideas básicas a partir de las cuales se respalda en el presente trabajo la necesaria restitución de los contenidos y valores humanísticos en la formación universitaria.

\section{I. Ante la falacia de la "especialización": formación integral y transversalidad}

A causa del referido fenómeno de la "practicidad" de los estudios superiores -incubado bajo un sesgado entendimiento de lo "útil", como se ha señalado-, surge también el debate de la "especialización", que corre igualmente el riesgo de ser ejecutado de manera parcial y simplificada. A este respecto, es un hecho comprobado que la distinción, y distancia, que se imponen entre ciencias técnicas y ciencias humanísticas cobra cada vez más fuerza. Incluso desde temprana edad exigimos ya a nuestros hijos, a través de las asignaturas optativas o actividades extraescolares, que hagan la elección del itinerario académico que seguirán en el futuro, barajando las dos opciones correspondientes a ciencias o a humanidades. Números o letras, suele decirse. Lo significativo es el hecho de la disyuntiva: o uno u otro. Crucial dicotomía que se obliga hoy día como necesaria. Y, ciertamente, se hace necesario elegir, pero el sistema educativo ha llegado a tal extremo de polarización en el que, por desgracia, elegir un camino supone automáticamente sacrificar el otro, implica cortarlo de raíz. Por eso cabe preguntarse: $\dot{\text { Existe el }}$ riesgo de que el alumno sufra pérdidas importantes de información y habilidades al centrar su aprendizaje en las herramientas exclusivas de su campo de estudio y renegar de aquellas otras que aparentemente le resultan ajenas a dicho campo?

7 R. ROMÁN AlCALÁ (2013), http://www.diariocordoba.com/noticias/opinion/en-defensa-defilosofia_779164.html. consulta realizada el 07/05/2013. 
Un asentimiento categórico se impone aquí como insalvable respuesta ante los resultados de esta especialización excluyente. Si el sistema vigente favorece con creces la elección de los itinerarios académicos de ciencias, en la convicción de su utilidad y empleabilidad, y trata como marginal los de humanidades, hallaremos, pues, profundos paréntesis en blanco dentro del aprendizaje de no pocos profesionales. Así por ejemplo, un ingeniero civil jamás estudiará lo que pensaba Platón de la organización de la polis. Raramente un economista conocerá las connotaciones sexuales del dinero según el psicoanálisis freudiano. Un gestor empresarial ignorará ampliamente el desarrollo político-económico en la historia de su país durante el siglo pasado. Es decir, nos acercamos peligrosamente a una realidad bicéfala que compartimenta la naturaleza de los estudios, haciendo de sus alumnos tullidos en lo formativo, y convirtiéndolos por extensión en futuros profesionales con limitado bagaje y menor gama de recursos a su alcance, lo cual empobrece de forma drástica su horizonte de miras y coarta su preparación humana y crítica ante la resolución de problemas, iniciativas de investigación y gestión del trabajo.

No se niega con esto la necesidad indiscutible de la especialización; lo que se critica es la especialización mal entendida, la especialización exclusivista y narcisista, que sólo se atiende a sí misma y que sólo observa su propia parcela de trabajo. Y es que a diferencia de lo que pueda pensarse en la actualidad, la especialización no significa centrarse en un sólo ámbito y olvidarse de los demás; por el contrario, consistiría en crecer y avanzar dentro de ese ámbito elegido pero sin cerrarlo al exterior y sin abortar su diálogo con otras áreas, lo cual le podría acarrear la pérdida de fructíferos resultados. Pues solamente emprendiendo viajes a otras zonas del conocimiento se puede aprender e innovar, y así, jugando con la analogía, podemos imaginar muy difícil la subsistencia de un individuo que permanezca siempre dentro del mismo territorio; terminarán por agotársele los víveres, y sólo saliendo de las fronteras de su hábitat en busca de alimento podrá sobrevivir y regresar después de nuevo a su ambiente, restituido en energía, renovado de perspectivas y reforzado en aprendizaje. Con esta vía abierta al diálogo se podrá enriquecer y reinventar constantemente el sector del que cada profesional sea especialista; de manera que se llega a la peculiar conclusión de que únicamente traspasando los límites de nuestra especialización lograremos ser cada vez más y mejores especialistas en nuestro sector. Así pues, no nos cerremos a la especialización; al llegar a la encrucijada, elijamos - pero no caigamos en la falsa idea de que tomar un camino trae consigo por obligación el abandono del otro. En realidad, es posible recorrer los dos; no de igual manera, lógicamente, pero ambos trayectos pueden llevarse en paralelo de forma que sea ventajoso para el itinerario principal por el que hemos optado, y para nosotros mismos en lo que nos atañe como personas. 
Semejante tentativa es, en efecto, viable. Suele olvidarse que, a pesar de sus diferencias y del empeño de los planes de estudios por separarlas por esta causa, ciencias y humanidades se entienden y se necesitan. Ambas son cultura, y como tal se interrelacionan. ${ }^{8}$ Se ha olvidado, insisto, que tanto unas como otras son producto de la creación humana, del pensamiento y sus arriesgadas aventuras, y constituyen ambas lo que se da en designar, universalmente, como cultura. Así lo argumentaba Ortega y Gasset cuando en Misión de la Universidad (1930) sostenía que la finalidad de la formación académica superior no era otra que la transmisión de cultura; entendiendo, claro está, por cultura no sólo las materias general e inexactamente llamadas humanísticas, sino toda la producción y creación del hombre, desde la ciencia a la literatura y del arte a la moral, para beneficio social y mejora colectiva del país. En la cultura se vive, esgrimiría Ortega. No es, por tanto, un añadido, sino un rasgo inseparable del ser humano y esencialmente característico de nuestra naturaleza; no es algo de lo que se pueda prescindir. La cultura no puede abordarse como algo que se da por añadidura, y mucho menos en la enseñanza superior; la cultura es un componente fundamental del ser persona, del ser estudiante, del ser profesional, del ser investigador. Por tanto, para Ortega la especialización no es comprensible como separación de humanidades y técnica -tanto la primera como la última se anquilosarían sin el apoyo recíproco de la otra. Se hace imprescindible mantener un equilibrio respetuoso, y por esto, también según Ortega y Gasset, la educación universitaria debe centrar sus objetivos en: a) la enseñanza de las profesiones intelectuales, y b) la investigación científica y la preparación de futuros investigadores.

Con lo cual, no se trata de impartir una cultura vaga aunque arqueológica, generalista pero esmerada en detalles intrascendentes, revestida con tintes de sabiduría. No es este tipo de cultura. Eso sería una cultura malograda. La cultura que debiera canalizar la universidad es el compendio del saber multidisciplinar de la creación humana; una cultura que, aun a riesgo de ser considerada "anti-utilitaria" $y$ "desinteresada" por el sentir mercantilista actual es, realmente, constituyente, constructiva, inquieta, práctica e innovadora. Secundemos, pues, de nuevo la opinión de Bertrand

\footnotetext{
${ }^{8}$ Nótese que hasta el siglo XIX, con la irrupción de las academias y la educación reglada institucionalizada por el estado, las materias que hoy llamamos ciencias estaban unidas a las que denominamos humanidades, y significativamente eran competencia de reflexión de los filósofos, que se ocupaban de los avances técnicos para sus estudios de óptica, astronomía, geografía, etc. Pongamos como ejemplo también el caso de las matemáticas o la física, que desde antiguo se consideraban campos del pensamiento filosófico, como podían serlo la metafísica, la ética o la política. Por lo tanto, no es tan real la diferenciación ramificada entre ciencias y humanidades; su sentido es simplificar y su función la de facilitar la docencia, pero la verdad de ambos sectores reside en la fusión con base en el hecho común de ser una creación cultural, como tal integral e interrelacionada.
} 
Russell: Para mí la cultura desinteresada tiene una gran importancia, y quisiera que en vez de disminuir aumentase su puesto en la vida académica. ${ }^{9}$ También Ortega y Gasset reivindica su importancia y destaca el riesgo de suprimir los ingredientes humanísticos en la formación profesionalista o investigadora, lo cual nos llevaría a ser algo así como unos nuevos bárbaros. No seamos "paletos de la ciencia", que diría el propio Ortega. Es decir, no seamos especialistas "parcelados", expertos de una materia concreta e ignorantes del resto de la producción cultural -en el amplio sentido orteguiano de la palabra-. De acuerdo con esto, la misión de la universidad es promocionar la enseñanza de las disciplinas culturales, lo cual no asume, como se ha visto, desprenderse del objetivo de componer un sujeto capaz y "profesionalizado", armado para desempeñar la labor para la cual se formó. Estamos hablando, en resumidas cuentas, de un tipo de educación integral, que en sí misma no se opone a la especialización, sino que precisamente persigue la puesta en marcha de una especialización "completa" y no únicamente sectorial; una especialización sustentada en el conocimiento más allá de las marcas limítrofes de aquellos intereses demandados por su aplicación instantánea.

Ya se apuntaba con anterioridad: Estas palabras no pretenden ser sino un aviso de alerta ante el peligro de la especialización mal entendida. En este panorama, las humanidades son, con seguridad, las más apuradas víctimas de la segregación fronteriza de saberes, pues son ellas especialmente las que se resisten a una especialización que empobrezca; abogan por el contrario por una especialización integradora, buscan -aparente ironía- una "especialización generalizada". Como decía Salvador Pániker citando a Comte, la filosofía es "la especialidad de la generalización", y afirmaba también que como disciplina es hoy [un ejercicio] esencialmente marginal, y surge cuando los especialistas (biólogos, matemáticos, físicos, etc.) encuentran obstáculos en la frontera de su propia especialidad y plantean interrogantes transdisciplinarios. ${ }^{10} \mathrm{He}$ aquí que aun en su impuesta marginalidad, la filosofía, como materia humanística por excelencia, sigue operando como eje fundamental en aquellos resquicios en los que flaquean las ciencias técnicas. En este sentido, las humanidades tienen la fortuna de poder intervenir de manera transversal en las demás ciencias cual punto de anclaje, sin interferir negativamente en el desarrollo vertical de las mismas. Por tanto, las nociones humanísticas no dificultan ni impiden la transmisión efectiva de lo que compete al área de especialización. Su participación se traduce en un sustento horizontal básico e insustituible que permite fortalecer lo aprendido y abrir nuevas vías a partir de ello.

\footnotetext{
${ }^{9}$ B. RusSeLL (1974), pp. 222-3.

10 S. PÁNIIKER (1982), p 15.
} 
De esto se infiere la muy recomendable práctica de servirse de las disciplinas humanísticas con el objeto de mejorar la capacitación de los alumnos, su integridad como profesionales y su calidad intelectual, sin olvidar los requerimientos concretos de su especialización, dotando para ello los programas docentes con los oportunos ingredientes de la rama de humanidades. Estaríamos hablando, pues, de la ansiada formación integral que favorecen las humanidades. No se pase por alto en este contexto, en palabras de Francesc Solé Parellada-catedrático de Organización de Empresas de la Universidad Politécnica de Cataluña-, la riqueza de las humanidades como una oportunidad de formación horizontal para el saber, saber hacer, comportarse y saber ser. " Para hacer efectivo este tipo de formación, no sería tan ardua tarea diseñar programaciones que contemplaran un porcentaje aceptable de aspectos humanísticos relacionados con la materia de sus asignaturas. Pero si esto no fuera posible cabría la opción de recurrir a las asignaturas transversales (cross-curricular), de libre configuración o incluso a la organización paralela de cursos de complementación anexa. Podría tomarse como referencia el modelo modernizador de Francisco Giner de los Ríos, quien siendo consciente de la necesidad de insertar a sus alumnos en el entramado laboral una vez graduados, pero incapaz de abandonarlos a una formación incompleta, diseñó una exitosa mecánica:

De ahí la necesidad de especializar. Pero el enlace entre los diversos estudios de una facultad, escuela, etc., y aun de estos institutos entre sí, debería ser tal, según esa concepción, que el alumno, al proseguir la dirección particular a que le llevan sus inclinaciones y en que se prepara para el desempeño de una profesión, libre o reglamentado, continuase sin interrupción, por una parte, a) recibiendo auxilio para el desenvolvimiento de su personalidad en todos sus aspectos, en la energía física como en el carácter moral; b) y en cuanto a los estudios, participando siempre a la vez, de un modo más o menos intenso, en otras ramas capaces de compensar la preponderancia de la suya, evitando la falta de horizonte de un especialista exclusivo y manteniendo la conciencia de la solidaridad entre todos los órdenes del conocimiento ${ }^{12}$

De estas raíces se nutrió el sistema aplicado en la Residencia de Estudiantes de Madrid, cuna de la Edad de Plata y "hogar" de un buen número de miembros de la Generación del 27 y las vanguardias españolas -en cuyas instalaciones, como es sabido, convivían poetas y científicos, músicos y escritores, pintores y biólogos, y se organizaban constantes conferencias de variada materia, a la par que actividades multidisciplinares, con el propósito de impulsar así las ciencias en conjunción con las letras y las artes-. Incluso limando los ideales de la época,

${ }^{11}$ F. Solé Parellada En AA.VV. (1998), P. 63.

${ }^{12}$ F. GINER DE LOS RÍOS (1990), p. 157. 
de corte krausista e institucionista, la propuesta de Giner de los Ríos no cae en una inocente reivindicación del "hombre renacentista" en unos tiempos en los que obviamente tal utopía incurriría en lo ilógico, sino que se trata de una práctica para la efectiva integración educativa; para la especialización en la confluencia de saberes y disciplinas. Más actual es el ejemplo de Martha Nussbaum en relación a la Universidad de New Hampshire, centro con el que esta Premio Príncipe de Asturias ha venido manteniendo una especial vinculación. En esta universidad se puso en marcha una medida consistente en ofertar cursos paralelos de contenido humanístico en el intento de proporcionar un encuadre formativo complementario a los alumnos de titulaciones no humanísticas. Estos cursos eran impartidos por un grupo de profesores procedentes de diversas áreas, desde Filosofía a Historia de la Ciencia, Teoría Política, Historia del Arte, Literatura comparada, etc., que trabajando en equipo, diseñaban una programación adecuada para suplir esas carencias detectadas en la formación académica no humanística. El éxito de este recurso en la citada institución llevó en varias ocasiones a sus propios departamentos a replantear el contenido de las guías docentes de los cursos regulares para dar cabida a un mayor aporte de humanidades.

Siguiendo este sistema transversal basado en cursos suplementarios se logra, por un lado, que los alumnos reciban una formación completa, útil y adecuada, y por otro, se evita forzar a profesores no expertos a impartir en sus asignaturas contenidos de humanidades que no entran en su especialidad. De este modo, se vela por la auténtica calidad y excelencia de la educación proporcionada a los estudiantes sin relegar a un segundo plano su preparación integral. Así pues, en opinión de Nussbaum, Deberían fomentarse fuertemente cursos con este tipo de enfoque, impartidos por docentes expertos, independientemente de qué otras áreas estemos impulsando. ${ }^{13}$ A pesar de todo, el sistema de enseñanza superior no debiera desentenderse de rectificar las titulaciones ya existentes para abrir hueco a las humanidades con títulos propios o mayor oferta de asignaturas optativas, pues son disciplinas que obviamente demandan mayor espacio de acción, confinadas siempre a un marco de intervención con escaso margen de movimiento. Citando de nuevo al prof. Ramón Román, las humanidades deben extenderse y contaminar todas las titulaciones. ${ }^{14}$ Finalmente, la ventana de la libre configuración sigue también abierta para reinventar su cometido y así, en vez de dedicarse a una mayor

\footnotetext{
${ }^{13}$ M. Nussbaum (2005), p. 109.

${ }^{14}$ R. Román Alcalá (2007), http://www. diariocordoba.com/noticias/educacion/ramon-roman-dptofilosofia-las-humanidades-deben-extenderse-y-contaminar-todas-las-titulaciones-_296623.html. Consulta realizada el 07/05/2013.
} 
especialización sectorial, vuelque parte de su disponibilidad en las humanidades y compense de esta forma la atención puesta en la formación "microespecializada". Como el Prof. Llano Cifuentes, docente de Filosofía y antiguo rector de la Universidad de Navarra, me atrevo a hacer sólo una elemental propuesta, que aquí también ha sido hecha ya: que nos tomemos en serio las materias de libre elección o de libre configuración, porque me parece que en los nuevos planes de estudios, tan polémicos por otros motivos, esas materias pueden proporcionar un complemento muy interesante a técnicos y científicos. ${ }^{15}$

Aún así, a pesar de las diferentes alternativas sugeridas, no es cosa sencilla habilitar estas modificaciones en el esquema educativo actual, teniendo en cuenta la dificultad de los horarios, los créditos, la disponibilidad docente, etc. Sin embargo, no debemos perder de vista lo fundamental: Quizá sea oportuno hacernos eco, una vez más, de la opinión de Fernando Savater, que nos recuerda que, a pesar de todo, lo verdaderamente esencial no es tanto el número de horas o créditos concretos que se imparten, sino la manera en que se imparten: inducir a aprender, motivar la curiosidad, impulsar la autonomía de pensamiento, la ilusión por crear... Si es importante el qué, también lo es el cómo. Y así, probablemente lo oportuno sea combinar ambos ingredientes. Para formar personas y no autómatas profesionalizados. Personas y ciudadanos posicionados en el mundo; un mundo que sepan entender y no sólo en el que sepan intervenir cualificadamente, sino conocer por qué y cómo se interviene. Sujetos pensantes, prácticos, productivos, resolutivos.

\subsection{Herramientas para la actitud crítica, el aprendizaje y el ser}

Decíamos antes que no es admisible formar individuos que cuenten sólo con los mecanismos técnicos mínimamente suficientes para el desempeño de su labor profesional. El individuo que surja de semejante acondicionamiento no será más que un mero engranaje en un sistema de producción, que poco podrá aportar de novedad para el crecimiento del mismo, dada su limitada formación. Por el contrario, un sujeto, en el pleno sentido del término, implica la conjunción de la vertiente práctica de su especialización técnica con el bagaje que-realmente necesario-le aportan las humanidades. Que éste último no sea tan evidente como los resultados expresados en un diagrama de barras no significa que no existan resultados relativos a las humanidades, o que incluso admitiendo su existencia, no sean éstos importantes, beneficiosos o útiles. Abramos, pues, nuestro entendimiento; liberémonos de las

\footnotetext{
${ }^{15}$ AA.V. (1998), p. 26.
} 
anteojeras que impiden que miremos lateralmente a la amplitud de territorios que traen consigo el resto de disciplinas. $Y$ es que un sistema de educación superior no puede permitirse formar solamente al homo faber, sino que debe, por propia responsabilidad, formar también a un homo sapere; un hombre que "sepa", que tenga conocimiento y no sólo conocimientos, y que tenga conocimiento no sólo de su pequeña área de acción sino también del abanico cultural merecedor de una atención enriquecedora para sí y para su profesión. En definitiva, como dijera con frecuencia Giner de los Ríos, hay que educar, no sólo instruir:

Entre nosotros, las personas de talento son periodistas, catedráticos, clérigos, comerciantes, ministros, naturalistas, fabricantes, médicos, militares, abogados, músicos, escritores, químicos, arquitectos y qué sé yo más... pero difícilmente son hombres. De aquí su estrecho especialismo, su indiferencia mortal hacia todo plus ultra de su reducido horizonte, y ese profundo divorcio entre la instrucción y la educación, no sólo en cuanto a la vida moral, sino en la misma esfera de la inteligencia $[\ldots.] .^{16}$

En esta línea, realizando el desglose de principios para la aplicación de su sistema de enseñanza, incluye don Francisco el siguiente punto, plenamente ejemplificativo:

Por último, durante toda la serie de los estudios técnicos, no debe abandonarse la educación y cultura generales, porque el hombre no deja de serlo para hacerse ingeniero. Así, verbigracia, al par de los estudios propios del ingeniero de minas, deben continuarse desenvolviendo los de las ciencias puras más conexionadas con su profesión (física, química, geología, etc.), aunque evidentemente con menor desarrollo que los de su especialidad, y tratando no más que de conservar despierto y animado el espíritu científico, de cuyos progresos dependen fundamentalmente todos los de las artes y aplicaciones técnicas. Para compensar la parcialidad, impedir la estrechez y el exclusivismo, mantener flexible, libre y abierto el espíritu a la todos los grandes problemas e intereses humanos, la primera garantía es esa comunicación de lo especial con lo general; y así como el abogado, o el literato, o el filósofo se avergüenzan, y con razón, de ignorar las teorías y descubrimientos de un Darwin, o lo que representan en el mundo Bessemer o Siemens, así el ingeniero debe avergonzarse de no saber quiénes fueron Shakespeare, Kant o Rousseau, o por qué principios deben gobernarse las naciones. ${ }^{17}$

El objetivo es, se deduce lógicamente, el de formar personas. Pero antes de tachar dicha expresión de inservible para los objetivos actuales, despojémosla del cúmulo de ideas pseudo-románticas que inmediatamente solemos agregarle y que corren el riesgo de lastrarla. Nada más lejos de la intencionalidad de la misma. Formar personas quiere decir formar esos sujetos que, siendo tales, puedan desarrollar su profesión y producir a partir de ella mejoras que dinamicen su propio sector y que

${ }^{16}$ F. GINER DE LOS RíOS (2004), P. 286.

17 Ibidem, p. 324. 
se proyecten en el progreso de la sociedad. Así pues, si eliminamos de la persona aquellas ventajas que pueda tener frente al "autómata especializado", a saber, el pensamiento divergente, el sentido crítico y la creatividad, habremos marcado un gol en nuestra propia portería, puesto que lo que podría haber sido un motor de avance ha quedado cortado en seco. El sistema de enseñanza superior parece no darse cuenta de esta realidad, a tenor de los resultados de las constantes reformas que ha experimentado $-y$ sufrido, por lo general- en el reciente tiempo de nuestra democracia. En este panorama, y a pesar de su cada vez más ardua subsistencia, las humanidades siguen esforzándose por transmitir el conjunto de aspectos formativos propios de las áreas de su rama, en un ambiente que para nada les es favorable y que dista mucho de ayudarlas en la consecución de sus objetivos, resumidos, como se ha especificado, en el propósito esencial de formar personas. En esta labor toman parte una serie de recursos en los que se condensan lo que podríamos considerar las "habilidades humanísticas" más destacables:

1. Remarquemos en primer lugar, que las humanidades, sustentadas primordialmente en el lenguaje (que somos) -como nos recuerda siempre Emilio Lledó-, facilitan las herramientas necesarias para la comprensión y apuntalan el intelecto haciéndolo capaz de aprehender ideas y desarrollar contenidos, o dicho de otro modo, de captar argumentos, seguir planteamientos y construir procesos dialécticos. Por lo tanto, las humanidades "trabajan" en varios niveles: uno, relacionado con la propia adquisición de conocimientos, otro; relativo a los procesos de comprensión que se ejecutan a partir de los conocimientos aprendidos; $y$ un tercero, vinculado a los mecanismos de construcción mental a los que éstos dan pie. En consecuencia, podemos decir que las humanidades sientan, por un lado, las bases para el aprendizaje en su fase más elemental (adquirir conocimiento), y por otro, para el desarrollo del entendimiento y el pensamiento (primero comprensión y después reflexión -creación de nuevas ideas; ideas propias-).

2. Después de asentar los cimientos de la estructura cognoscitiva, las humanidades procuran que germine el pensamiento autónomo, es decir, la reflexión sobre los conocimientos que se han asimilado (aprendido y comprendido). En esta fase entran en juego el sentido crítico, la creatividad y la capacidad de involucrarse en problemáticas de diversa índole para construirse una opinión propia de las mismas, proponer alternativas, difundir ideas, etc. Se trata de la posibilidad de perfilar un posicionamiento autosubjetivante que sea, al mismo tiempo, la fase inicial de próximas secuenciaciones de creación. Todo ello radica, una vez más, en la particular capacidad de reflexionar que es propia de las humanidades, o en otras palabras, su capacidad crítica. Es el espíritu crítico, la capacidad 
de toma de decisiones conociendo variables que, de otra manera, a uno le serían negadas. Ese espíritu crítico creo que tiene que ver con lo que solemos entender como espíritu humanístico. ${ }^{18}$

3. Finalmente, la formación en humanidades reviste una vertiente ética que de otra forma sería imposible adquirir, y que tiene directa aplicación en el mundo profesional y en la vida en general. Una perspectiva que en buena medida determina las acciones que se emprenden y cómo se emprenden, permitiendo ver más allá de los resultados al alcance de la mano para valorar así otras implicaciones colaterales que afectan a elementos ajenos a la ecuación principal que nos ocupa en cada situación. Por eso, las humanidades ayudarían a guiar la actitud de los estudiantes universitarios, futuros profesionales, a decantar su forma de entender el mundo, a encontrar su lugar en el mismo, a decidir su itinerario profesional $o$ investigador, y a ayudarles a trabajar para llevarlo a efecto satisfactoriamente. Como puede apreciarse, no tiene esto por qué contradecir la cultura técnica imperante, pero sí desde luego la complementa y pule para combatir sus deficiencias a causa del exclusivismo de la especialización.

Arribamos así a la conclusión de que las humanidades manifiestan, en esencia, una importante influencia de carácter ontológico que les es definitoria y que se despliega por necesidad en la formación académica. De este modo, su ausencia en los planes de estudio se percibe como tal; como una laguna. Las "herramientas" que canalizan las humanidades no son, pues, aspectos prescindibles. No son sencillamente una complementación recomendada por sus aspectos positivos; son instrumentos básicos e insustituibles de una correcta enseñanza académica. Por lo tanto, su progresiva marginación en las titulaciones universitarias se traduce en una irremplazable carencia; en un vacío insalvable, desde lejos perceptible, que relega al olvido herramientas tan relevantes como las que enumera el prof. Llano Cifuentes -cuatro valores que le sirven para reivindicar las humanidades y su inclusión en los programas docentes tanto de "ciencias" como de "letras":

Primero, las humanidades como interpretación crítica de la realidad actual. Segundo, las humanidades como revitalización de la cultura. Tercero, las humanidades como reflexión sobre las grandes cuestiones personales y sociales. Cuarto, las humanidades como catalizadores de la creatividad. ${ }^{19}$

18 J. M. URIBE Oyarbide en AA. VV. (1998), p. 86.

${ }^{19}$ A. Llano Cifuentes en AA. VV. (1998), p. 19. 
Vemos así cómo el conocimiento humanístico se multiplica en destrezas prácticas cuyos resultados no reportan, probablemente, indicios tan mesurables como los que se extraen de disciplinas técnicas, pero la productividad de los mismos está más allá de toda duda. No se caiga tampoco en el estereotipo según el cual poseer conocimiento humanístico es amueblar la cabeza con datos históricos curiosos e intrascendentes: no es tampoco excusa -como a veces se hace- argumentar que contamos con accesibles depósitos de información (ya sea libros o más especialmente internet) a los que acudir para consultar contenidos humanísticos cuando éstos se necesiten. Es innegable este hecho, pero el valor y la utilidad de las humanidades van mucho más allá de recitar de memoria el listado de los reyes godos... Tener conocimiento no es equivalente a ser meros depositarios, cual despensa intelectual, de nombres, fechas u otros datos, sino que equivale a ser; a identificarse, a construir, a crear, a impulsar. He aquí la clave fundamental de la que dimanan las demás, y que terminarán de exponerse en el siguiente y último apartado.

\subsection{Creatividad, innovación y emprendedurismo}

Decía Jeremy Rifkin (La era del acceso, 2000) que Ésta va a ser la era de las ideas y el capital intelectual, será lo que fue el vapor o la electricidad. ${ }^{20}$ No será este modesto artículo el lugar donde se le lleve la contraria a Rifkin, pero si en efecto ésta va a ser la era de las ideas, lo único cierto es que difícilmente podremos obtenerlas sin una formación transdisciplinar y variada. Si las ideas van a ser el motor y el baluarte de nuestra época, como en su momento lo fueron el vapor o la electricidad, probablemente avanzaremos poco si no se alimenta como es debido la locomotora del saber, que queda muy empobrecida si prescindimos de la parcela vertebradora de las humanidades. Lo hemos venido diciendo: si en la enseñanza académica faltan las humanidades, el resultado será una formación jalonada de taras, ya que escasearían la inventiva, la crítica y la creatividad, habilidades que se entrenan gracias al conocimiento humanístico. Y esto no es cosa baladí, pues parece que ignoremos el alcance de estas destrezas... ¿ $\dot{\imath}^{N o}$ son acaso fundamentales para el correcto despliegue de las necesidades de una empresa, por ejemplo? Pues es de suponer que no hay empresa que no tenga entre sus objetivos crecer, innovar o emprender. Retos imposibles de alcanzar si no se ponen en práctica las capacidades de un intelecto formado en reflexión y creación. El problema es harto sabido: la especialización obvia estos factores mientras, irónicamente, pretende alentar el talento y el emprededurismo.

\footnotetext{
${ }^{20}$ Citado por F. Gallego Reinoso (2001), p. 11.
} 
En nuestra opinión, la especialización "narcisista" -que no la integradora que aquí se propone- se conduce según un esquema jerárquico que le impide atender esta problemática. Se conduce, más en concreto, según un tipo de pensamiento que Edward de Bono llama "vertical" y que opone al "pensamiento lateral". El pensamiento vertical es una forma de pensamiento habitual y "normalizado", que permite la continuidad de la vida diaria y la existencia cotidiana, se mueve siempre en un mismo ámbito y sigue un sentido unidireccional incluso a pesar de intentar dinamizar su marco de actuación. El pensamiento vertical no se sale de sus raíles. En contraposición, el pensamiento lateral es, como su nombre indica, transversal por naturaleza; abre así nuevas rutas y nuevas perspectivas de conjugación de ideas diversas, y sirve para paliar las limitaciones del vertical. Con el pensamiento lateral 'nos desplazamos hacia los lados, para probar diferentes percepciones, diferentes conceptos, diferentes puntos de entrada. ${ }^{21}$ El pensamiento lateral, que es sinónimo de pensamiento creativo, ayuda a escapar de la preponderancia de las viejas ideas o de las ideas ya conocidas, de las ideas dominantes.

Pues bien, las humanidades favorecen con ímpetu esta ruptura con la estructura arborescente del pensamiento vertical, al interrelacionar y contrastar áreas del saber, conceptos, tradiciones y actitudes intelectuales. Por eso son fundamentales para aportar soluciones dinámicas o enriquecer disyuntivas prácticas; por eso rompen las fronteras entre ciencias técnicas y no técnicas:

Cuando se aborda un problema es corriente dar por sentado un conjunto de límites dentro de los cuales debe encontrarse la solución. Las fronteras del problema se definen por presunción y entonces, dentro de esas fronteras, el pensamiento vertical se propone encontrar la solución. Sin embargo, muy a menudo las fronteras son imaginarias y la solución puede estar fuera de ellas. ${ }^{22}$

En este sentido, se hace necesario tener en cuenta que el pensamiento vertical es un grueso impedimento para el desarrollo de la creatividad ${ }^{23}$, en un tiempo en que la capacidad creativa se considera, cada vez más, la única ventaja competitiva real (Sólo si nuestras empresas llegan a ser este hervidero de innovación y

${ }^{21}$ E. DE BONO (2009), p. 96.

${ }^{22}$ E. DE BONO (2008), p. 110.

${ }^{23}$ Dice E. de Bono que uno de los principios básicos del pensamiento lateral es darse cuenta de que el pensamiento vertical, por su naturaleza, no es solamente ineficaz cuando se trata de generar nuevas ideas, sino también fehacientemente inhibidor. E. DE BONO (2008), p. 115. 
de creatividad, podrán enfrentarse a los desafíos europeos e internacionales. ${ }^{24}$ ). Así pues, Imaginemos una persona encerrada durante años a pan y agua en una cueva, desprovista de toda estimulación y de cualquier tipo de herramienta. ¿Podría crear algo ex nihilo, a partir de esa nada225 Por tanto, es esencial que esta persona haga incursiones en territorios ajenos a su especialización; en caso contrario, se verá imposibilitada para su pleno desarrollo creativo, ya que el sujeto creativo aplica en la elaboración de sus "productos" aquellos contenidos mentales y nociones cognoscitivas que le son familiares. Resultará así dinamitado el proceso creativo, que, según suele definirse, consta de dos fases: la de exploración y la de aplicación, correspondiéndose la primera con la creatividad y la segunda con la innovación. En la fase de exploración, se generan y se manipulan nuevas ideas, se combina el material no relacionado entre sí, se hacen conexiones distintas a las habituales y se buscan pautas no usuales. Uno imagina, vagabundea, quebranta las normas y deja que las ideas fermenten en el segundo plano de su mente. ${ }^{26}$ Con lo cual, si no salimos de nuestro círculo no habrá lugar en el que vagabundear, y si no abonamos un intelecto inclinado a la pregunta y al discurrir argumental, pocas oportunidades tendremos de poder aplicar los logros que supuestamente hallemos en la fase de exploración, que ya de por sí serán escasos. En resumen, se necesita lo que Guilford dio en llamar "pensamiento divergente"; un tipo de pensamiento creador, fluido y adaptativo.

Regresemos a beber a la fuente de las humanidades. Ellas nos reportan las habilidades del espíritu creativo.

¿Qué aportan las humanidades a una investigación cuyo núcleo parece ser el científicotécnico? Yo diría que el sueño, la capacidad de soñar, la ilusión, el entusiasmo por el saber nuevo y esta capacidad sistémica, lo que los alemanes de finales del siglo XVIII y comienzos del XIX, los grandes ilustrados y románticos llamarían imaginación trascendental, es decir, la capacidad de forjar esquemas conceptuales, inventados o reales. ${ }^{27}$

$Y$ recordemos con esto que la creatividad es algo que se tiene que formar, y que es imposible suplir con actividades empresariales de grupo, sistemas de trabajo o técnicas más o menos acertadas con la finalidad de estimular a los trabajadores

\footnotetext{
${ }^{24}$ B. Prouvost (1991), p. 35.

${ }^{25}$ R. RABADÁn ANTA (2011), p. 24.

${ }^{26}$ F. GAllego Reinoso (2001), p. 22.

${ }^{27}$ A. Llano Cifuentes en AA. VV. (1998), p. 25.
} 
a actuar "creativamente". De nada sirve. Incidimos en una profunda falsedad determinada por el mismo objetivo de la rentabilidad descorazonada. La realidad es que no hay fórmulas "precocinadas" para hacer a la gente más creativa, por mucho que se empeñen teóricos como William Gordon (sinéctica), Alex Osborn (brainstorming) o Delbecq y Van de Ven ("TGN" -Técnica del grupo nominal"), o incluso inventores de tests - de nuevo, la significativa manía por testar-como el reciente "CREA" (Corbalán, Martínez, Donoloy otros). Supuestamente nos afanamos por descubrir y fomentar el talento, la innovación y la actitud emprendedora, pero no impulsamos las medidas que serían oportunas para ello, y lo que es más, las que desarrollamos tienden a reducir sus posibilidades de crecimiento... Intentamos codificar "ecuaciones matemáticas" que aplicándolas en un tiempo aceptable nos ayuden a diferenciarnos y a hacernos líderes. Craso error. Cuando se recomienda "cultivar el espíritu creativo" se está haciendo, en realidad, una llamada subliminal a un retorno a las cualidades de las humanidades, pero no sabemos darnos cuenta ni llevarlo a cabo, pues, en palabras de Walter Benjamin,

Al orientar desde un principio a los estudiantes hacia fines profesionales, se deja, necesariamente, escapar, como algo estimulador, el poder inmediato de la creación. [...] La misteriosa tiranía de la idea de profesión es la más profunda de estas falsificaciones. Lo que tiene de más terrible es que todas ellas llegan al centro de la vida creadora, aniquilándola. ${ }^{28}$

Como ya se ha indicado, las humanidades son simiente de pensamiento y cambio, y su razón de ser, promesa de creatividad, no cae en saco roto, sino que es plenamente útil incluso para los objetivos de rentabilidad de nuestro entramado económico. De hecho,

La creatividad está despertando cada vez un mayor interés y una gran expectativa en la práctica de la gestión empresarial y organizacional así como en todas las áreas del pensamiento, de la educación y de la cultura. Poco a poco, la creatividad va dejando de ser una prerrogativa de sectores muy exclusivos y de un grupo muy reducido de personas: artistas, diseñadores, publicistas. [... Dicho de otro modo, la creatividad en la organización ya no es un lujo que se ofrece al personal, sino una necesidad, una fuerza vital para las empresas, para que se puedan mantener en entornos cada vez más exigentes y más competitivos. ${ }^{29}$

En esta línea se expresa también José Luis Alberto Aguirre, quien fuera Vicepresidente del Consejo Social de la Universidad Pública de Navarra: Yo, particularmente, me sumo a la consideración de excelentes de las humanidades. Desde el punto de vista

${ }^{28}$ Citado por E. LLedó (2009), p. 157.

29 B. Prouvost (1991), p. 16. 
empresarial cada vez se aprecia más al pensador, al que tiene la formación íntegra, al filósofo. ${ }^{30}$ Dado entonces este convencimiento, deberíamos preguntarnos sobre el modo de facilitar semejante formación integral: ¿Cuál es el modo de reforzar esta transversalidad estructurale La única vía es regresar, como hijos pródigos, a las esferas de la cultura, el saber y la reflexión, que antes habíamos considerado inservibles. El pensamiento es creatividad; la filosofía es un producto creativo, el arte es un producto creativo, la literatura es un producto creativo. Son creaciones del ser humano. Volvamos, pues, por necesidad a las humanidades.

\section{Notas conclusivas}

A pesar de los desesperados intentos, en tiempos recientes, por revestir de "calidad" y "excelencia" el sistema educativo, la realidad difiere considerablemente de estos objetivos, pues tendríamos que cerrar los ojos a la situación actual de la enseñanza para ignorar que el nivel y la auténtica calidad de la educación se deterioran a pasos agigantados. Baste con observar el grado de conocimiento, de capacitación, de implicación personal y la actitud general del amplio porcentaje de los estudiantes universitarios que ocupan hoy sus asientos en las aulas españolas. Nunca se había hablado tanto de calidad, y nunca había escaseado tanto. Mucho tiene que ver en esto esa especialización sectorial y estadística que, irónicamente, se deja por el camino la ansiada calidad en la formación de sus estudiantes, pretendiendo alcanzar estándares de "competencias", aparentemente más útiles y rentables, a los cuales se les supone la potestad de marcar la diferencia entre lo que "es de calidad" y lo que no. Persiguiendo, pues, unas ideas en sí mismas dignas de alcanzar, lo que se está aplicando es el deforme reflejo de esos ideales, una imagen especular, un esperpento: estudiantes que reciben una formación cribada, personas cultivadas a la carta, sujetos moldeados para insertarse en su hueco de la maquinaria sistémica para hacerla funcionar.

En estas circunstancias, deberíamos retornar cuanto antes a los valores de transdisciplinariedad y de cultura formativa que en este artículo venimos defendiendo. Aunque no figure entre las competencias ambicionadas en la actualidad, formar personas es sin duda un objetivo de calidad. Formar personas -personas profesionalizadas, recordémoslo- es el horizonte integral que nos asegura una mayor excelencia, tanto en cuanto a la formación de los universitarios, a la preparación de los futuros profesionales, y a la entereza de personas con valía para la colectividad.

\footnotetext{
${ }^{30}$ AA. V. (1998), p. 17.
} 
No es ésta otra cosa que la "excelencia" de las humanidades; una excelencia que va filtrándose en el entramado social para beneficio de su organización cívica, cultural y productiva. Retomando así nuestro afán transversalizante, terminamos con una pregunta lanzada al aire por Emilio Lledó:

La discusión sobre el sentido de las Ciencias Humanas se ha reavivado en nuestros días por la presión que ejercen determinados desarrollos tecnológicos y la consiguiente ideología de la utilidad y el dinero que ha invadido las nuevas perspectivas del capitalismo. Pero estas discusiones han olvidado, muchas veces, el originario modelo de esas Humanidades en cuyos contornos se vislumbraba una interpretación total de la existencia. ¿No sería, por otra parte, contradictorio que ahora que se habla tanto de globalización, nos olvidásemos de globalizar, integrar, humanizar los saberes?31

\section{Bibliografía}

AA.VV. (1998), La presencia de las humanidades en la formación universitaria. II Jornadas de Trabajo del Consejo Social de la Universidad Pública de Navarra, Pamplona, Dirección de Publicaciones Universidad Pública de Navarra.

Aróstegul, J. L. y Martínez Rodríguez, J. B. (2008), Globalización, Posmodernidad y Educación. La calidad como coartada neoliberal, Madrid, Universidad Internacional de Andalucía, Akal.

Bauman, Z. (2006), Vida líquida, Barcelona, Paidós.

- (2013), Sobre la educación en un mundo líquido: conversaciones con Ricardo Mazzeo, Barcelona, Paidós.

DE BONO, E. (2008), El pensamiento lateral práctico, Barcelona, Paidós.

- (2009), El pensamiento creativo. El poder del pensamiento lateral para la creación de nuevas ideas, Barcelona, Paidós.

Gallego Reinoso, F. (2001), Aprender a generar ideas: Innovar mediante la creatividad, Barcelona, Paidós Ibérica.

GINER DE LOS Ríos, F. (1990), Escritos sobre la universidad española, Madrid, Colección Austral, Espasa Calpe.

${ }^{31}$ E. LLEDÓ (2009), pp. 91-2. 
- (2004), Obras selectas, Madrid, Austral Summa.

LLEDÓ, E. (2009), Ser quien eres. Ensayos para una educación democrática, Zaragoza, Prensas Universitarias de Zaragoza.

LLOVEt, J. (201 1), Adiós a la universidad. El eclipse de las Humanidades, Barcelona, Galaxia Gutenberg. Círculo de Lectores.

Moscoso, J. (2013), "Las humanidades del siglo XXI", $A B C, 11 / 05 / 2013$, p. 3.

Muñoz-Repiso, M., Murillo, F. J. y ArRImadas, I. (1998), "¿Hay lugar para la enseñanza de las humanidades en la Europa del siglo XXI?", Revista Española de Educación Comparada, n 4, pp. 209-235.

Nussbaum, M. (2005), El cultivo de la humanidad: una defensa clásica de la reforma en la educación liberal, Barcelona, Paidós.

Ortega NaVAS, Ma del C. (coord.) (2012), El valor de la educación (Liber amicorum). Estudio interdisciplinar en homenaje al profesor Dr. D. Emilio López-Barajas Zayas, catedrático emérito de universidad, Navarra, Editorial Universitas.

Ortega y Gasset, J. (2007), Misión de la universidad, Madrid, Biblioteca Nueva.

PÁNIKER, S. (1982), Aproximación al origen, Barcelona, Kairós.

Prouvost, B. (1991), Innovar en la empresa. Las claves del éxito, Barcelona, Marcombo-Boixareu Editores.

RabadÁn ANTA, R. y Corbalán Berná, J. (2011), Creatividad: Teoría y práctica elemental para profesionales de la docencia, la empresa y la investigación, Córdoba, Servicio de Publicaciones de la Universidad de Córdoba.

Román Alcalá, R. (2005), "Humanidades, lo primero", Diario Córdoba, 18/05/2005, http://www.diariocordoba.com/noticias/cultura/humanidadeslo-primero_186627.html. Consulta realizada el 07/05/2013.

- (2007), Entrevista, Diario Córdoba, 24/01/2007, http://www. diariocordoba. $\mathrm{com} /$ noticias/educacion/ramon-roman-dpto-filosofia-las-humanidades-debenextenderse-y-contaminar-todas-las-titulaciones-_296623.html. Consulta realizada el 07/05/2013. 
- (2013), "En defensa de la Filosofía", Diario Córdoba, 31/01/2013, http:// www.diariocordoba.com/noticias/opinion/en-defensa-de-filosofia_779164.html. Consulta realizada el 07/05/2013.

RusselL, B. (1974), Ensayos sobre educación, Colección Austral, Espasa Calpe, Madrid.

Savater, F. (2008), El valor de educar, Barcelona, Ariel.

Zamora Bonilla, J. (2010), "El futuro de las humanidades. ¿̇Tienen futuro las Humanidades?", Tribuna Complutense, 27/04/2010, p. 4. 